\title{
SIG APLICADO NA CARACTERIZAÇÃO MORFOMÉTRICA DA MICROBACIA DO RIBEIRÃO MORRO GRANDE - BOFETE, SP
}

\author{
Rafael Calore Nardini \\ Sérgio Campos \\ Andrea Cardador Felipe
}

RESUMO: Esse trabalho objetivou a aplicação de geoprocessamento na caracterização morfométrica da microbacia do Ribeirão Morro Grande - Bofete (SP) através do Sistema de Informação Geográfica - Selva, visando à preservação, racionalização do seu uso e recuperação ambiental. A microbacia apresenta uma área de 4049ha e está localizada entre os paralelos $22^{\circ} 50^{\prime} 05^{\prime \prime}$ a $22^{\circ} 54^{\prime} 26^{\prime \prime}$ de latitude $S$ e $48^{\circ} 22^{\prime} 29^{\prime \prime}$ a $48^{\circ} 26^{\prime} 36^{\prime \prime}$ de longitude W Gr. A base cartográfica utilizada foi a carta planialtimétrica de Bofete (SP), em escala 1:50.000 (IBGE, 1968) na extração das curvas de nível, da hidrografia e da topografia, em ambiente de Sistema de Informações Geográficas - Idrisi Selva, para determinação dos índices morfométricos. Os resultados mostram que os baixos valores da densidade de drenagem, associados à presença de rochas permeáveis, facilitam a infiltração da água no solo, diminuindo o escoamento superficial e o risco de erosão e da degradação ambiental, bem como o baixo valor do fator de forma amparado pelo índice de circularidade indica que a microbacia tende a ser mais alongada com menor susceptibilidade à ocorrência de enchentes mais acentuadas. O parâmetro ambiental coeficiente de rugosidade permitiu classificar a microbacia para vocação com floresta e reflorestamento.

Palavras-chave: Morfometria. Hidrografia. SIG. 


\section{INTRODUÇÃO}

O uso adequado dos recursos naturais exige estudos aprofundados par que sejam compreendidos os possíveis impactos provocados pela ação antrópica (Queiróz, 2008).A caracterização fisiográfica da microbacia do Ribeirão Morro Grande - Bofete (SP) é essencial para a elaboração e implementação de futuros projetos agroambientais regionais, pois os resultados auxiliarão na compreensão do escoamento superficial da mcirobacia.

As características físicas das microbacias são de suma importância, pois atuam no ciclo hidrológico, influenciando diretamente nos aspectos relacionados com a infiltração, a evapotranspiração e o escoamento superficial e subsuperficial (Rodrigues et al., 2008).

O conhecimento dessas características físicas permite numa determinação do desenvolvimento do escoamento superficial numa determinada localidade, possibilitando a formulação de medidas preventivas no controle de enchentes, caso a microbacia seja susceptível a esse tipo de evento. (Fontes et al., 2008 e Cardoso et al., 2006).

A morfometria é uma ferramenta fundamental no diagnóstico de susceptibilidade á degradação ambiental, delimitação da zona ripária, planejamento e manejo de microbacias (Moreira e Rodrigues, 2010), pois a sua caracterização permite descrever a formação geomorfológica da paisagem em sua variação topográfica (Christofoletti, 1980), bem como possui um papel significativo no condicionamento de respostas ligadas à erosão hídrica, gerado após eventos pluviométricos relevantes (Arraes et al., 2010).

O monitoramento contínuo dos recursos hídricos é um instrumento essencial para melhor avaliar os fenômenos hidrológicos críticos, envolvendo tanto as secas quanto inundações. Com a adequada avaliação dos recursos hídricos utilizando o monitoramento dos dados relativos a uma microbacia por exemplo, pode-se propor uma adequação da ocupação do solo em relação ao seu potencial e de suas limitações, tornando possível um manejo racional e equilibrado com a natureza, conquistando assim a sustentabilidade.

O sistema de informação geográfica (SIG) utiliza uma base de dados computadorizada que contém informação espacial (aspectos no meio natural como relevo, solo, clima, vegetação, hidrologia, etc., e os aspectos sociais, econômicos e políticos, que permitem uma divisão temática em subsistemas que integram um SIG, sendo esses componentes os atributos), sobre a qual atua uma série de operadores espaciais 
(conjunto de operações algébricas, booleanas e geométricas, utilizadas no cruzamento de dados pelo SIG). Verifica-se que a principal característica dos SIGs é focalizar o relacionamento de determinado fenômeno da realidade com sua localização espacial. Podem-se estudar outros aspectos mais complexos, como a vizinhança e contigüidade envolvendo áreas extensas (Teixeira et al., 1992).

O presente trabalho teve como objetivo a caracterização morfométrica da microbacia do Ribeirão Morro Grande - Bofete (SP) em ambiente do Sistema de Informações Geográficas Idrisi Selva, visando o planejamento e o manejo integrado dos recursos hídricos da área.

\section{MATERIAL E MÉTODOS}

A microbacia do Ribeirão Morro Grande localiza-se na porção norte do município de Bofete-SP, entre as coordenadas geográficas $48^{\circ} 22^{\prime} 29^{\prime \prime}$ a $48^{\circ} 26^{\prime} 36^{\prime \prime}$ de longitude WGr. e $22^{\circ} 50^{\prime} 05^{\prime \prime}$ a $22^{\circ} 54^{\prime} 26^{\prime \prime}$ de latitude S, com uma área de 4049 ha.

O clima predominante do município, classificado segundo o sistema Köppen é do tipo Cwa - Clima subtropical úmido com invernos secos e verões quentes - em que a temperatura do mês mais frio é inferior à $18^{\circ} \mathrm{C}$ e do mês mais quente ultrapassa os $22^{\circ} \mathrm{C}$.

$\mathrm{Na}$ caracterização morfométrica da área foi utilizada a carta planialtimétrica do IBGE (1969), em escala 1:50.000, folha Bofete-SF-22-R-IV-3, com curvas de nível de 20 em 20 metros, para extração da rede de drenagem (Figura 1) e da planialtimetria (Figura 2).

O Software Idrisi Selva foi utilizado para vetorização das curvas de nível, do divisor de águas, da rede de drenagem, bem como para elaboração da análise morfométrica, hierarquia dos canis, de acordo com Strahler (1952).

Após a delimitação da área da bacia obteve-se as características dimensionais da rede de drenagem (Figura 1), que são parâmetros quantitativos que permitem eliminar a subjetividade na sua caracterização. Na determinação desses parâmetros foi seguida a metodologia citada por Oliveira \& Ferreira (2001) no cálculo do maior comprimento (C), do comprimento do curso principal (CP), do comprimento total da rede $(C R)$, do perímetro $(P)$ e da área (A), as quais foram obtidas através do software Sistema de Informações 
Geográficas Idrisi Selva utilizado para manipulação, tratamento e análise dos dados gerados como as curvas de nível (Figura 2) e a rede de drenagem da microbacia.

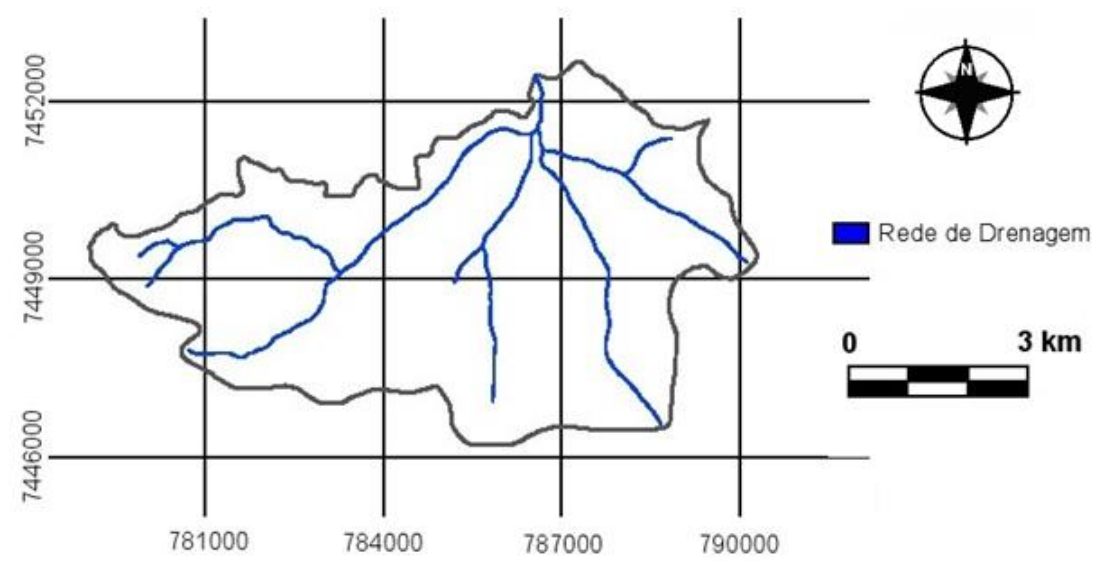

Figura 1. Hidrografia da microbacia do Ribeirão Morro Grande - Bofete (SP) (Strahler, 1952).

$\mathrm{Na}$ definição da hierarquização da rede de drenagem foi seguida a metodologia proposta por Horton (1945) e modificada por Strahler (1957). O parâmetro ordem dos canais se refere a uma classificação sobre o grau de ramificações e/ou bifurcações presentes em uma bacia hidrográfica. A classificação de ordenamento dos cursos mais utilizada é a proposta por Horton (1945) e modificada por Strahler (1957).

$\mathrm{Na}$ caracterização da composição e padrão de drenagem foram analisados os seguintes parâmetros: a densidade de drenagem (Dd), a extensão do percurso superficial (Eps), a extensão média do escoamento superficial (I), a textura da topografia (Tt), o coeficiente de manutenção $(\mathrm{Cm})$, a rugosidade topográfica (Rt) e o índice de forma $(\mathrm{K})$ foram determinados a partir da metodologia desenvolvida por Christofoletti (1969), bem como, o fator de forma (Kf) foi determinado pela metodologia utilizada por Almeida (2007).

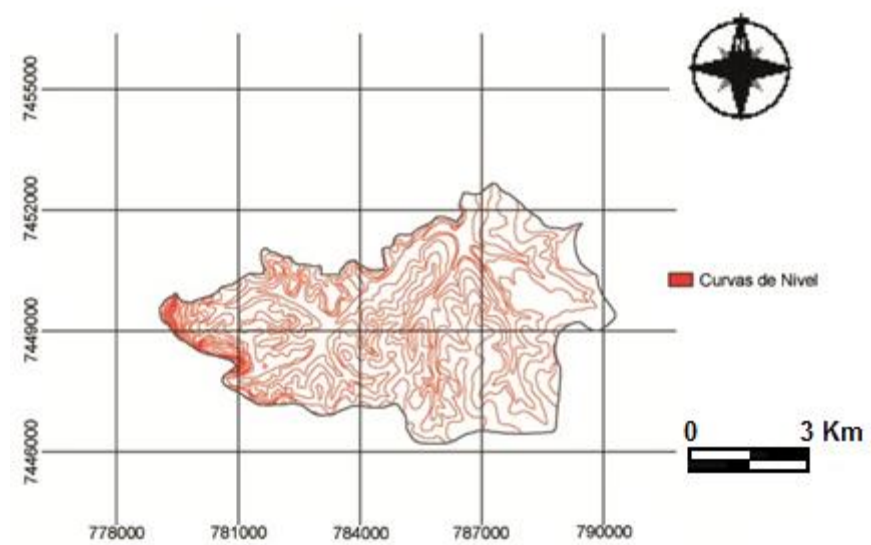


Figura 2. Planialtimetria da microbacia do Ribeirão Morro Grande - Bofete (SP) (Strahler, 1952).

\section{Densidade hidrográfica (Dh)}

A densidade hidrográfica é a relação existente entre o número de rios ou canais e a área da bacia hidrográfica (Christofoletti, 1969), sendo expressa pela equação:

$$
D h=N \cdot A^{-1}
$$

Onde:

Dh - Densidade hidrográfica em $\mathrm{km}^{-2}$

$\mathrm{N}$ - Número total de rios

A - Àrea da bacia hidrográfica em $\mathrm{km}^{2}$

\section{Declividade média}

A magnitude dos picos de enchente e de infiltração de água, trazendo como consequencia maior ou menor grau de erosão, depende da declividade média da bacia (que determina a maior ou menor velocidade de escoamento da água superficial), associada à cobertura vegetal, tipo de solo e tipo de uso da terra (Rocha \& Silva, 2001). A declividade média foi obtida a partir da fórmula abaixo e classificada segundo Lepsch et al., 2001 (Tabela 1):

$$
H=(D . L) 100 / A
$$

onde:

$\mathrm{H}$ - Declividade média em \%

D - Distância entre as curvas de nível em m

$\mathrm{L}$ - Comprimento total das curvas de nível em $m$

A - Área da microbacia em $\mathrm{m}^{2}$ 
Tabela 1. Classes de declividade e relevo (Lepsch et al, 2001).

\begin{tabular}{|c|c|}
\hline Classes de Declividade & (\%) Relevo \\
\hline $0-3$ & Plano \\
\hline $3-6$ & Suave ondulado \\
\hline $6-12$ & Ondulado \\
\hline $12-20$ & Forte ondulado \\
\hline $20-40$ & Montanhoso \\
\hline$>40$ & Escarpado \\
\hline
\end{tabular}

\section{Coeficiente de rugosidade (CR)}

O coeficiente de rugosidade $(\mathrm{CR}=\mathrm{Dd} . \mathrm{H}$, onde: $\mathrm{CR}=$ coeficiente de rugosidade; $\mathrm{Dd}=$ densidade de drenagem e $\mathrm{H}=$ declividade média), por ser um parâmetro que direciona o uso potencial das terras rurais, dependendo das características das atividades - agricultura, pecuária, silvicultura com reflorestamento ou preservação permanente -, foi usado para definir as classes de uso da terra das cinco microbacias hidrográficas da bacia do rio Soledade, que são: $A$ (menor valor de $C R$ ) - terras apropriadas à agricultura; $B$ terras apropriadas à pecuária; $C$ - terras apropriadas à pecuária e reflorestamento e $D$ (maior valor de CR) - terras apropriadas para florestas e reflorestamento, segundo Rocha \& Silva (2001).

As classes A, B, C e D para caracterização do uso potencial da terra de cada microbacia foram obtidas através do cálculo da amplitude, que é a diferença entre o maior e o menor valor de CR encontrada para as bacias de terceira ordem de ramificação e o intervalo de domínio - amplitude dividida por 4 -, que é o número de classes preconizadas pelo método de Sicco Smith (Rocha \& Silva, 2001).

\section{Densidade de drenagem (Dd)}

A densidade de drenagem é a correlação do comprimento total dos rios com a área da bacia, sendo obtida a partir da fórmula (Silva et al., 2004):

$D d=I . A^{-1}$ 
Onde:

Dd - Densidade de drenagem em $\mathrm{km} / \mathrm{km}^{2}$

L - Comprimento total dos rios ou canais em $\mathrm{km}$

A - Área da bacia em $\mathrm{km}^{2}$

Segundo Christofoletti (1969) a densidade de drenagem pode ser classificada em três classes de interpretação (Tabela 2)

Tabela 2. Classes de interpretação para os valores da densidade de drenagem (Christofoletti (1969).

\begin{tabular}{|c|c|}
\hline Classes de valores $\left(\mathbf{k m}^{2}\right)$ & Densidade de drenagem \\
\hline$<7,5$ & Baixa \\
\hline 7,5 a 10,0 & Média \\
\hline$>10,0$ & Alta \\
\hline
\end{tabular}

Índice de circularidade (IC)

O índice de circularidade, também denominado por alguns autores como índice de forma, representa a relação existente entre o perímetro e a área da bacia. O número calculado independe da área considerada, dependendo apenas da forma da bacia (Silva et al., 2004). O menor valor possível a ser encontrado é 1,0, correspondendo a uma bacia circular (Gandolfi, 1971). Esse parâmetro influencia a determinação da vazão e a intensidade de escoamento (Silva et al., 2004). O índice de circularidade foi determinado pela equação:

$$
\mathrm{TC}=12,57 P^{2}
$$

Onde:

K - Índice de circularidade;

$P$ - Perímetro da bacia em $\mathrm{km}$

A - Área da bacia em $\mathrm{km}^{2}$ 


\section{Coeficiente de Compacidade (Kc)}

O coeficiente de compacidade é a relação entre o perímetro da microbacia e o perímetro de uma circunferência de um círculo de área igual da microbacia, que de acordo com Villela e Mattos (1975) é um número adimensional que varia com a forma da microbacia, independentemente de seu tamanho. Se a bacia for irregular, maior será o coeficiente de compacidade e menos sujeita à enchentes, sendo: $\mathrm{Kc}=1-1,25$ (redondas para ovaladas); 1,25 - 1,50 (ovaladas); 1,50 - 1,70 (blongas).

$\mathrm{Na}$ determinação do Kc utilizou-se da fórmula:

$$
K c=0,28\left(P: A^{1 / 2}\right)
$$

Onde:

Kc - Coeficiente de compacidade

$P$ - Perímetro em metros

A - Área de drenagem em $\mathrm{m}^{2}$

\section{Fator de forma (Ff)}

A forma de uma microbacia pode ser comparada conforme algumas figuras geométricas conhecidas. Assim, o coeficiente de compacidade, o índice de circularidade compara a microbacia a um círculo e o fator de forma a compara a um retângulo. A forma da microbacia e a configuração do sistema de drenagem, estão associadas a estrutura geológica do terreno.

Este fator é mito importante, pois, segundo Villela e Mattos (1975), uma microbacia apresenta um fator de forma baixo quando é menos sujeita a enchentes que outra de mesmo valor de área, porém com fator de forma maior.

O fator de forma $(F)$ pode ser determinado pela seguinte equação:

$$
F=A / L^{2}
$$

Onde:

F - Fator de forma

A - A área de drenagem em $\mathrm{m}^{2}$ 
L - O comprimento do eixo da bacia em $m$

\section{Razão de Relevo}

A razão de relevo é a relação entre a diferença de altitude dos pontos extremos da bacia e seu comprimento (Schumm, 1956).

A razão de relevo (Carvalho, 1981) demonstra que, quanto maiores os valores, mais acidentado será o relevo na região. Quanto maior a razão de relevo, maior será a declividade geral da bacia, portanto maior será a velocidade da água a escoar no sentido de seu maior comprimento. Piedade (1981) utilizou os seguintes valores para quantificar a razão de relevo: Razão de relevo baixa - 0,00 a 0,10; média - 0,11 a 0,30 e alta - 0,31 a 0,60 .

\section{RESULTADOS E DISCUSSÃO}

A análise dos resultados obtidos para a microbacia do RibeirãoMorro Grande (Figuras 1 e 2 e Tabela 3) mostra que a área é de 4049ha, o perímetro de 33,37km e o fluxo de água se dá na direção SW-NE da microbacia, com um comprimento de 8,09km. O comprimento total da rede de drenagem é de $33,53 \mathrm{~km}$, demonstra que a microbacia apresenta-se com poucos canais de drenagem.

O formato é caracterizado fisicamente por parâmetros que relacionam com formas geométricas conhecidas, como o fator de forma que relaciona a um retângulo e o coeficiente de compacidade que relaciona a um círculo (Rodrigues et al., 2011).

A forma é um parâmetro importante na determinação do tempo de concentração, pois determina o tempo necessário para que toda a mcirobacia contribua na saída da água após uma precipitação, uma vez que quanto maior o tempo de concentração menor será a vazão máxima de enchentes. $O$ baixo valor do fator de forma $(0,62)$ obtido para 0 ribeirão Morro Grande indica que a microbacia tem o formato mais ovalado. 
Tabela 3. Características morfométricas da microbacia Ribeirão Descalvado, BotucatuSP.

\begin{tabular}{|c|c|c|}
\hline Características físicas & Unidades & Resultados \\
\hline \multicolumn{3}{|c|}{ Parâmetros dimensionais da microbacia } \\
\hline Área $(\mathrm{A})$ & $\mathrm{Km}^{2}$ & 40,49 \\
\hline Perímetro $(\mathrm{P})$ & $\mathrm{Km}$ & 33,37 \\
\hline Comprimento do Rio Principal (C) & $\mathrm{Km}$ & 8,09 \\
\hline Comprimento da rede de drenagem total $(\mathrm{Cr})$ & $\mathrm{Km}$ & 29,87 \\
\hline Comprimento das curvas de nível (Cn) & $\mathrm{Km}$ & 291,71 \\
\hline \multicolumn{3}{|c|}{ Características do relevo } \\
\hline Coeficiente de compacidade (Kc) & --- & 1,47 \\
\hline Fator forma (Ff) & --- & 0,62 \\
\hline Índice de circularidade (Ic) & --- & 0,46 \\
\hline Declividade média (D) & $\%$ & 14,41 \\
\hline Altitude média (Hm) & $\mathrm{m}$ & 717,5 \\
\hline Maior altitude (MA) & $\mathrm{m}$ & 935 \\
\hline Menor altitude $(\mathrm{mA})$ & $\mathrm{m}$ & 500 \\
\hline Amplitude altimétrica $(\mathrm{H})$ & $\mathrm{m}$ & 435 \\
\hline Coeficiente de Rugosidade (CR) & --- & 8,65 \\
\hline \multicolumn{3}{|c|}{ Padrões de drenagem da microbacia } \\
\hline Ordem da microbacia $(\mathrm{W})$ & --- & $3^{\mathrm{a}}$ \\
\hline Densidade de drenagem (Dd) & $\left(\mathrm{km} / \mathrm{km}^{2}\right)$ & $0,6 \mathrm{Km} / \mathrm{Km}^{2}$ \\
\hline Coeficiente de Manutenção (Cm) & $\left(\mathrm{m} / \mathrm{m}^{2}\right)$ & 1,66 \\
\hline Extensão do Percurso Superficial (Eps) & $\mathrm{m}$ & 833,33 \\
\hline Gradiente de Canais (Gc) & $\%$ & 9,9 \\
\hline Índice de Sinuosidade (Is) & - & 1,24 \\
\hline Frequencia de Rios (Fr) & - & 1,51 \\
\hline Densidade Hidrográfica & $\left(\mathrm{km} / \mathrm{km}^{2}\right)$ & 1,89 \\
\hline
\end{tabular}

A área de uma microbacia é de extrema importância, pois ela influencia na quantidade de água produzida como deflúvio. A forma e o relevo atuam sobre a taxa e o regime desta na produção de água e na taxa de sedimentação. 
O coeficiente de compacidade maior do que $1(1,47)$ e o fator de forma baixo $(0,62)$ permitiram afirmar que a microbacia, em condições normais de precipitação, excluindo-se eventos de intensidades anormais, é pouco susceptível a enchentes. Portanto, os resultados desses parâmetros mostram que a microbacia não possui formato circular, tendendo para a forma alongada, elíptica (Santos, 2001; Rocha \& Silva, 2001) e apresenta menor risco de enchentes sazonais, bem como o valor do índice de circularidade de 0,46 permitiu confirmar também que a microbacia não possui forma próxima à circular, isto é, apresenta forma alongada.

Os baixos valores de Dd, Fr e Razão, provavelmente, estão associados à presença de rochas permeáveis (Tonello et al., 2006), pois facilita a infiltração da água no solo diminuindo o escoamento superficial e o risco de erosão e degradação ambiental, pois quanto maiores esses valores mais intenso é o processo de erosividade do solo (Rodrigues et al., 2008).

As características da rede de drenagem da microbacia mostram que a densidade de drenagem foi de $0,6 \mathrm{~km} / \mathrm{km}^{2}$ e a densidade hidrográfica de $1,89 \mathrm{~km} / \mathrm{km}^{2}$. Christofoletti (1969) afirma que a densidade de drenagem da microbacia é baixa, pois o valor é menor que $7,5 \mathrm{~km} / \mathrm{km}^{2}$, enquanto que para Villela \& Mattos (1975), esse índice pode variar de $0,5 \mathrm{~km} / \mathrm{km}^{2}$, em microbacias com drenagem pobre, $3,5 \mathrm{~km} / \mathrm{km}^{2}$ ou mais, em microbacias excepcionalmente bem drenadas, indicando que a microbacia do Ribeirão Morro Grande apresenta baixa drenagem, indicando que esses valores baixos de densidade de drenagem estão geralmente associados a regiões de rochas permeáveis e de regime pluviométrico caracterizado por chuvas de baixa intensidade ou pouca concentração da precipitação.

A sinuosidade é um dos fatores controladores da velocidade de escoamento do canal, pois quanto mais próximo da unidade, demonstra que o rio segue exatamente a linha do talvegue, ou seja, apresenta-se com baixo grau de sinuosidade (Silva et al., 2009).

O valor médio da extensão do percurso superficial e do coeficiente de manutenção confirma a presença de solos permeáveis na microbacia.

A classificação e o mapeamento da declividade do terreno são elementos indispensáveis nos levantamentos de uso da terra, constituindo-se num elemento de 
suma importância no condicionamento de sua potencialidade de utilização, segundo Marques (1971).

Para Silva \& Piedade (1993), o conhecimento e a representação detalhada do relevo de uma área constituem-se em elementos indispensáveis ao planejamento das atividades agropastoris, à elaboração de projetos de engenharia, ao levantamento e conservação de solos, aos estudos hidrológicos, etc.

Segundo Mota (1981), a declividade do terreno contribui para o escoamento das águas das chuvas sendo que, quanto maior for o trecho em declive, menor será o escoamento das águas pela superfície e, consequentemente, maior será a possibilidade de erosão, vindo a concordar com Amaral \& Audi (1972) que afirmam que o relevo é considerado um dos mais importantes critérios de fotopedologia. Juntando-se a fatores climáticos e pedológicos, o relevo comanda a capacidade de infiltração, além de determinar o tipo de escoamento superficial.

O conhecimento da declividade de um solo pode ser obtido de diversas maneiras, em campo e em laboratório, para estudos geológicos, hidrológicos, pedológicos, etc. A declividade pode ser obtida a partir de fotografias aéreas verticais para fins de estudos geológicos (Avery, 1962) e a partir de cartas planialtimétricas (Coelho, 1972).

Para Politano (1978), o relevo apresenta relações diretas com as condições de profundidade do perfil, susceptibilidade à erosão, drenagem, etc.

A declividade média na microbacia do ribeirão Morro Grande - Bofete (SP), da ordem de 14,41 permitiu classificá-la (Chiarini \& Donzeli, 1973) como relevo como forte ondulado, sendo impróprio para o cultivo de culturas anuais e indicado para a o uso de pastagens em eventual rotação com culturas anuais, podendo ser também exploradas com culturas permanentes que protegem o solo (café, laranja, cana-de-açúcar, leguminosas como forma de adubação verde, etc.), pois são terras sujeitas à erosão e a prática da conservação do solo é imprescindível (Lepsch et al., 1991). Portanto, atividades agrícolas em áreas impróprias e de forma inadequada deve ser considerada como uma prática de risco, pois se as práticas conservacionistas não forem utilizadas nestes casos, as bacias sofrerão grandes perdas de solos por erosão.

Para Moreira et al. (2010), a declividade quanto mais alta apresenta relação direta com os processos erosivos devido à maior velocidade de escoamento superficial e menor 
infiltração das águas das chuvas, propiciando alteração na regulagem do sistema hidrológico e produção de água na mcirobacia.

O coeficiente de rugosidade por ser um parâmetro que direciona o uso potencial da terra com relação às suas aptidões para agricultura, pecuária ou reflorestamento (Rocha, 1991), mostra também a realidade de uma microbacia, oferecendo uma contribuição simples, rápida e precisa ao planejamento, para melhor e mais justa exploração econômica, em função da vocação de suas terras (Pereira Filho, 1986), pois existe uma alta correlação entre o coeficiente de rugosidade e a capacidade de uso da terra, ao nível de $0,5 \%$ de erro.

O coeficiente de rugosidade é utilizado para diagnosticar as probabilidades de vir a ocorrer erosões. Desta forma, coeficiente de rugosidade de 0,08646 permitiu classificar a microbacia do Ribeirão Morro Grande para vocação com uso por agricultura (Classe A), segundo Rocha (1991), uma vez que os altos valores do coeficiente de rugosidade mostram que estas têm maiores chances de sofrer os efeitos da erosão, necessitando de medidas para prevenção e maior taxa de áreas cobertas pela vegetação.

\section{CONCLUSÕES}

A morfometria da microbacia do Ribeirão Morro Grande permitiu concluir que as variáveis morfométricas servirão para futuros planejamentos e gestões ambientais regionais. A microbacia apresenta altos riscos de susceptibilidade à erosão e degradação ambiental, sendo fundamental a manutenção da cobertura vegetal e as zonas ripárias para conservação dos serviços ambientais. $O$ fator de forma e a densidade de drenagem, classificado como baixo, permitem inferir que o substrato tem permeabilidade alta com maior infiltração e menor escoamento da água. O Sistema de Informações Geográficas Idrisi Selva foi uma excelente ferramenta para a viabilização do monitoramento e gestão dos recursos hídricos da microbacia. O coeficiente de rugosidade permitiu classificá-la para vocação com uso por Agricultura (Classe A), pois altos valores mostram que estas têm maiores chances de sofrer os efeitos da erosão, necessitando de medidas para prevenção e proteção com cobertura vegetal. 
ALMEIDA, A.Q. de. 2007. Influência do desmatamento na disponibilidade hídrica da bacia hidrográfica do Corrego do Galo, Domingos Martins, ES. Dissertação (Mestre em Engenharia Ambiental) Espírito Santo - Brasil Julho -2007 Programa de PósGraduação Em Engenharia Ambiental - Centro Tecnológico - Universidade Federal do Espírito Santo, Vitoria, ES, 2007.

AMARAL, A.Z., AUDI, R. Fotopedologia. In: MONIZ, A.C., (Coord.) Elementos de fotopedologia. São Paulo: EDUSP, v.42, p.429-442, 1972.

ARRAES, c.l. ET AL. Morfometria dos compartimentos hidrológicos do Município de Jaboticabal, SP. Unopar., Londrina, v.9, n.1, p.27-32, 2010.

AVERBECK, H., SANTOS, R.D. Manual de fotointerpretação para solo. Rio de Janeiro, Minist. Agric., 1989. 33p.

AVERY, E.T. Interpretation of aerial photographs. 2.ed. Arizona: Barvass, 1962. 321p.

CARDOSO, C.A.; DIAS, H.C.T.; BOECHAT, C.P. 2006. Caracterização Morfométrica da Bacia Hidrográfica do Rio Debossan, Nova Friburgo/RJ. Revista Árvore, 30, 2, 241-248.

CARVALHO, W.A. Relações entre relevos e solos da bacia do rio Capivara município de Botucatu, SP. Botucatu, (Tese de Livre-Docência) - FCA/UNESP, 1981. $193 f$.

CHIARINI, J.J., DONZELLI, P.L. Levantamento por fotointerpretação das classes de capacidade de uso das terras do Estado de São Paulo. Bol.Tec.Inst.Agron., Campinas, n.3, p.1-29, 1973.

CHRISTOFOLETTI, A. Análise morfometrica das bacias hidrográficas. Notícia Geomorfologia, Campinas, 9(18):35-64, 1969.

CHRISTOFOLETTI, A. Geomorfologia. 2.ed. São Paulo: Edgard Blucher, 1980.

COELHO, A.G. de S. Obtenção de dados quantitativos de fotografias aéreas verticais. Aerofotogrametria, São Paulo, 1972, v.8, p.1-23.

FONTES, M.P., OLIVEIRA, A.S., SANTOS, D.E., CONCEIÇÃO, J.A., PINTO, L.A., LISBOA, V.A.C., MELLO JÚNIOR, A.V. Análise comparativa das características de duas sub-bacias de Sergipe com uso de técnicas de geoprocessamento. In: SIMPÓSIO REGIONAL DE GEOPROCESSAMENTO E SENSORIAMENTO REMOTO, 5, 2008. Anais... Aracajú: Instituto Nacional de Pesquisas Espaciais - INPE, 2011. p.3947.

GANDOLFI, P.A. 1971. Investigações sedimentológicas, morfométricas e físioquímicas nas bacias do Moji-Guaçu, do Ribeira e do Peixe. Tese (Livre Docência). Departamento de Geologia e Mecânica dos Solos, EESC-USP, São Carlos, SP. 
HORTON, R. E. Erosional development of streams and their drainage basins: hidrophysical

appoach to quantitative morphology. Bull. Geol. Soc. Am., Colorado, v. 56, n. 3, p. 275370, 1945.

LEPSCH, J.F. et al. Manual para levantamento utilitário do meio físico e classificação de terras no sistema de capacidade de uso. Campinas, Soc.Bras.Cien.do Solo, 2001.175p.

MARCHETTI, D.A.B., GARCIA, G.J. Princípios de fotogrametria e fotointerpretação. São Paulo: Nobel, 1978.

MOREIRA, L., RODRIGUES, V.A. Análise morfométrica da microbacia da Fazenda Edgárdia - Botucatu (SP). Eletr.Eng.Florestal. Garça, v.16, n.1, p.9-21, 2010.

MOTA, S. Planejamento urbano e preservação ambiental. Fortaleza, Edições UFC, 1981.242p.

OLIVEIRA, A., FERREIRA, E. 2001. Caracterização de sub-bacias hidrográficas. Lavras: UFLA/FAEPE, 64p. Textos Acadêmicos. Curso de pós-graduação Revista Brasileira de Geografia Física 03 (2010) 112-122.

PEREIRA FILHO, W. Capacidade de uso da terra em função do coeficiente de rugosidade. 1986. 48 f. Monografia - Universidade Federal de Santa Maria, Santa Maria, 1986.

PIEDADE, G.C.R. Evolução de voçorocas em bacias hidrográficas do município de Botucatu, SP. Botucatu, (Tese de Livre Docência) - FCA/UNESP, 1980. $161 \mathrm{f}$.

QUEIRÓZ, H.A. Caracterização fisiográfica e de alguns atributos físicos e químicos dos solos da mcirobacia Jardim Novo Horizonte, em Ilha Solteira, SP. Dissertação (Mestrado em Asgronomia). Faculdade de Engenharia de Ilha Solteira - UNESP, Ilha Solteira - SP. 61p. Espírito Santo - Brasil Julho -2007 Programa de Pós-Graduação Em Engenharia Ambiental - Centro Tecnológico - Universidade Federal do Espírito Santo, Vitoria, ES, 2007.

ROCHA, J. S. M. da. Manual de Manejo Integrado de Bacias Hidrográficas. Santa Maria: Edições UFSM, 1991. 181 p.

RODRIGUES, D.P., NOLASCO, M.C., JESUS, T.B. Geoprocessamento aplicado ao estudo da análise morfométrica: o caso da microbacia do rio Coisa Boa - Igatu - Chapada Diamantina - BA. In: SIMPÓSIO BRASILEIRO DE SENSORIAMENTO REMOTO, 15, 2011, Curitiba. Anais... São José dos Campos: Instituto Nacional de Pesquisas Espaciais - INPE, 2011. p.3947.

RODRIGUES, F.M.; PISSARRA, T.C.T.; CAMPOS, Caracterização morfométrica da microbacia hidrográfica Córrego da Fazenda Glória, Município de Taquaritinga. Irriga, Botucatu, v. 13, n.3, p. 310-322, 2008. 
SCHUMM, S.A. Evolution of drainage systems and sloes in bedlands at Perth Amboy. New Jersey. Bull. Geol. Soc. Am., Colorado, v.67, p.597-646, 1956.

ROCHA, J.S.M. da.; SILVAI Kurtz, S.M. de J.M.. 2001. Manual de Manejo Integrado de Bacias Hidrográficas, 4a ed. - Santa Maria: Edições UFSM CCR/UFSM 302p.

SILVA, A.M.; SCHULZ, H.E.; BARBOSA, C.P.. 2004. Erosão e Hidrossedimentologia em Bacias hidrográficas. São Carlos : RiMa. 141p.

SILVA, M.S., PIEDADE, G.C.R. Análise do relevo de uma bacia hidrográfica através da curva de distribuição percentual da superfície em função de suas declividades parciais. In: CONGRESSO BRASILEIRO DE ENGENHARIA AGRÍCOLA

SILVA, M.S., PIEDADE, G.C.R. Análise do relevo de uma bacia hidrográfica através da curva de distribuição percentual da superfície em função das suas declividades parciais. In: CONGRESSO BRASILEIRO DE ENGENHARIA AGRÍCOLA, 22, 1993. Anais... Ilhéus - BA, CEPLAC/SBEA, 1993. P.362-373.

STRAHLER, A.N. 1952. Hypsometric analysis of erosional topography. Geol. Soc. America

Bulletin, 63, pp. $1117-1142$.

STRALHER, A. N.. Quantitative analysis of watershed geomorphology. Trans. Am. Geophys. Un., New Haven, v.38, p.913-20, 1957.

TEIXEIRA, A.L.A., MORETTI, E., CRISTOFOLETTI, A. Introdução aos sistemas de informação geográfica. Rio Claro, SP, 1992, 80p.

TONELLO, K.C. DIAS, H. C. T., SOUZA, A. L. de., RIBEIRO, C.A. A.S. R. \& LEITE, F.P (2006). Análise hidroambiental da bacia hidrográfica da cachoeira das Pombas, Guanhães, MG. R. Árvore, Viçosa-MG, v.30, n.5, p.849-857, 2006.

VILLELA, S.M.; MATTOS, A. 1975. Hidrologia Aplicada. São Paulo. 